\title{
Pathological assessment of Nigella sativa oil and its chitosan loaded nanoparticles on experimental hepatic cystic echinoncoccosis
}

Original

Article

\author{
Shereen M Kishik ${ }^{1}$, Ibrahim M Nagati ${ }^{1}$, Ibrahim $R$ Ali $^{2}$, Nagwa SM Aly ${ }^{1}$, Maha M \\ Fawzy $^{1}$, Hemat S Ali ${ }^{1}$
}

Departments of Parasitology ${ }^{1}$, Faculty of Medicine, Benha University, Benha, and Immunoparasitology ${ }^{2}$, Theodor Bilharz Research Institute, Imbaba, Giza, Egypt

\begin{abstract}
Background: Hydatid cyst is one of the most common cysts detected in the liver. Surgery is the preferred approach in treatment, but surgery may have serious complications as anaphylaxis, implantation of scolices, and formation of secondary cysts. Medical treatment with surgery decreases probability of these complications.

Objectives: To evaluate the efficacy of Nigella sativa oil (NSO), Albendazole (ABZ) and chitosan nanoparticles (CS NPs) as drug carrier to increase the efficacy of ABZ and NSO.

Material and Methods: Mice were infected with E. granulosus scolices and classified according to drugs schedule into five groups (G): G (3) was infected and treated with ABZ; G (4) was infected and treated with NSO; G (5) was infected and treated with NSO and ABZ; G (6) was infected and treated with ABZ loaded on CS NPs, G (7) was infected and treated with NSO loaded on CS NPs. Two control groups were assigned: G (1) was non infected non treated and G (2) was infected non treated. Four months post infection, mice were sacrificed and collected livers of each group were sectioned for histopathology.

Results: Histopathological studies revealed that groups treated with drugs loaded on CS NPs contained no hydatid cysts with improvement in the degree of inflammation, necrosis, and congestion of hepatic tissue. Conclusion: It was concluded that the best curative effect was observed in groups treated with drugs loaded on CS NPs.
\end{abstract}

Keywords: chitosan nanoparticles, hepatic tissue, histopathological evaluation, hydatid cyst, Nigella sativa oil.

Received: 25 January, 2021, Accepted: 2 March, 2021.

Corresponding Author: Hemat S Ali, Tel.: +20 1223088562, E-mail: hemat_salah@yahoo.com

Print ISSN: 1687-7942, Online ISSN: 2090-2646, Vol. 14, No. 1, April, 2021.

\section{INTRODUCTION}

Usually, cystic echinoncoccosis (CE) may progress silently over years and even decades until it presents with clinical manifestations that are mainly correlated to the site and size of cysts ${ }^{[1]}$. Surgical removal is the ideal method for the treatment of hydatid cysts ${ }^{[2]}$ while avoiding the spilling of hydatid fluid which is highly antigenic leading to acute anaphylaxis $\operatorname{shock}^{[3]}$. In addition, use of protoscolicidal agents is an important component of surgical treatment in order to avoid recurrence and formation of multiple secondary echinococcosis ${ }^{[4]}$. The medical treatment of CE is based on drugs of benzimidazole family, usually $\mathrm{ABZ}^{[5,6]}$.

It was reported that NSO (black seed or black cumin), that belongs to the Ranunculacea family, is a herbal medicine with many pharmacological properties ${ }^{[7]}$. Various pharmacological effects such as antioxidant, anti-inflammatory, anti-cancer, antimicrobial have been reported for use of NSO or its active principles that include thymoquinone, carvacrol, $\rho$-cymene, and thymol ${ }^{[8]}$. It is worth mentioning that NSO has been evaluated as scolicidal agent instead of chemotherapy in conjunction with surgery ${ }^{[9]}$.

It has been shown that the efficacy of the medical treatment in CE is based on the concentration of the drug and the diffusion capacity of the cyst layers for an adequate period of time ${ }^{[10,11]}$. Use of CS NPs produced mild protection in treatment of giardiasis ${ }^{[2]}$, increased the effect of ivermectin as anti-filarial drug ${ }^{[13]}$ and increased the effect of spiramycin in treatment of acute and chronic toxoplasmosis ${ }^{[14]}$.

In this study, we attempted to evaluate the histopathological effect of CS NPs as drug carrier for both NSO and ABZ, and their combination. The effect of NSO either as mono therapy or combined with ABZ on the condition of hepatic hydatid cysts was also investigated in experimentally infected mice. 


\section{MATERIAL AND METHODS}

The case-control study was conducted at Theodor Bilharz Research Institute (TBRI), Giza, Egypt, and Benha Faculty of Medicine during the period from March 2017 to July 2017.

Herbal extract, CS and ABZ: Oil of $N$. sativa (Pharco Pharmaceutical, Alexandria, Egypt) was obtained as soft gelatin capsule (450 $\mathrm{mg}$ ) and dissolved in $2 \mathrm{ml}$ distilled water ${ }^{[15]}$ to obtain a dose of $1.14 \mathrm{gm} / \mathrm{kg}^{[16]}$. While CS (93\% deacetylation degree) was provided from Sigma-Aldrich (USA), ABZ (Bendax) suspension form $(100 \mathrm{mg} / 5 \mathrm{ml})$ was obtained from Sigma Medical Company, St. Louis, MO, USA, and was given in a dose of $200 \mathrm{mg} / \mathrm{kg}^{[17]}$.

Preparation of CS NPs: The synthesis procedures were carried out according to the ionotropic gelation technique $^{[18]}$. Bendax loaded on CS NPs was given in a dose of $200 \mathrm{mg} / \mathrm{kg}$ and NSO loaded on CS NPs was given in a dose of $1.14 \mathrm{gm} / \mathrm{kg}$.

Parasites preparation: Cysts of E. granulosus were obtained from sheep lung at El-Warrak slaughterhouse in Cairo, Egypt. Under sterile conditions, the cysts were punctured to obtain the protoscoleces ${ }^{[19]}$. The acquired fluid was centrifuged and the sediment containing protoscoleces was washed with sterile phosphate buffer saline (PBS) (pH7.2-7.4, Sigma Chemical Company, St. Louis, MO, USA) and supplemented with $30 \mathrm{mg} / \mathrm{mL}$ gentamicin (GIBCO-BRL Life Technology, NY, USA) ${ }^{[20]}$.

Viability assay: Protoscoleces viability was determined by staining with $0.1 \%$ eosin. The protoscoleces viability was estimated microscopically by adding $10 \mu \mathrm{l}$ of eosin stock solution to $10 \mu \mathrm{L}$ of protoscoleces for $15 \mathrm{~min}$. The unstained protoscoleces with flame cells activity were considered as viable while the stained protoscoleces were considered dead ${ }^{[21]}$.

Mice infection: Each mouse was infected by intra peritoneal inoculation of nearly 1000 viable protoscoleces suspended in $500 \mu$ of sterile PBS $^{[22]}$.

Experimental animals: Forty laboratory-bred male Swiss albino pathogen-free adult mice, six to eight weeks old weighing 25-30 gm were used throughout this study. They were inbred at Schistosome Biological Supply Center, and were housed in the Experimental Animal Unit, Theodor Bilharz Research Institute (TBRI), Giza, Egypt. Mice were maintained under standard laboratory care $\left(25^{\circ} \mathrm{C}\right.$, with a relative humidity of 40 $60 \%$, normal diet of commercial pellets and potable water). Mice were classified into eight equal groups (Table 1).

Mice were tube fed orally with the drugs starting 2 months post infection ${ }^{[23]}$, and continued for another 2 months ${ }^{[19]}$. At the end of the study (4 months postinfection), mice were sacrificed, and livers were collected for histopathological studies.

Histopathological assessment of drugs efficacy: Small sections of the livers with localized cysts detected by the naked eye, were excised, fixed in $10 \%$ buffered formalin, mounted in paraffin blocks, and cut into 4-mm-thick sections. The sections were stained with Hematoxylin and Eosin stains and then studied histopathologically to evaluate structural alterations of the hepatic parenchymal cells ${ }^{[24]}$. The degree of architectural tissue changes and cellular infiltration was used as histological parameters. Images were captured from each slide with a digital camera (Casio) on a light microscope. Necro-inflammatory activity was scored according to the histological activity index (HAI) described by Mekonnen et al. ${ }^{[25]}$ as $0=$ absence, 1 $=$ mild, $2=$ moderate, and $3=$ severe .

Ethical consideration: All the animal experiments were performed according to the rules of the Scientific Research Ethical Committee, Faculty of Medicine Benha University. Also, animal handling and all procedures were done in agreement with the TBRI ethical guidelines.

\section{RESULTS}

The pathological picture of examined livers of different groups were in the form of inflammatory changes with infiltration of inflammatory cells (lymphocytes), necrotic changes, hydropic degeneration, congestion, and dilatation of the sinusoids. The severity of these finding varied from one group to another (Table 2 and Figure 1).

Table 1. Study groups.

\begin{tabular}{ll}
\hline \hline Groups & \multicolumn{1}{c}{ Characteristics } \\
\hline $\mathbf{1}$ & Non infected non-treated. \\
$\mathbf{2}$ & Infected and non-treated. \\
$\mathbf{3}$ & Infected and treated with ABZ $(200 \mathrm{mg} / \mathrm{kg})$. \\
$\mathbf{4}$ & Infected and treated with NSO $(1.14 \mathrm{gm} / \mathrm{kg})$. \\
$\mathbf{5}$ & Infected and treated with NSO $(1.14 \mathrm{gm} / \mathrm{kg})$ and ABZ $(200 \mathrm{mg} / \mathrm{kg})$. \\
$\mathbf{6}$ & Infected and treated with ABZ loaded on CS NPs $(200 \mathrm{mg} / \mathrm{kg})$. \\
$\mathbf{7}$ & Infected and treated with NSO loaded on CS NPs $(1.14 \mathrm{gm} / \mathrm{kg})$. \\
$\mathbf{8}$ & Infected and treated with ABZ loaded on CS NPs $(200 \mathrm{mg} / \mathrm{kg})$ and NSO loaded on CS NPs $(1.14 \mathrm{gm} / \mathrm{kg})$. \\
\hline \hline
\end{tabular}


PARASITOLOGISTS UNITED JOURNAL

Table (2): Comparison between different tested groups according to pathological changes and presence or absence of cysts in the liver.

\begin{tabular}{lccccc}
\hline \hline \multirow{2}{*}{ Groups } & \multicolumn{5}{c}{ Pathological changes in liver } \\
\cline { 2 - 6 } & Inflammation & Necrosis & Degeneration & Congestion & Hydatid cyst \\
\hline $\mathbf{1}$ & 0 & 0 & 0 & 0 & Absent \\
$\mathbf{2}$ & 3 & 3 & 3 & 2 & $\begin{array}{c}\text { Complete cyst wall with attached } \\
\text { scoleses to the germinative layer } \\
\mathbf{3}\end{array}$ \\
$\mathbf{4}$ & 2 & 2 & 2 & 1 & Remnant of cyst \\
$\mathbf{5}$ & 1 & 1 & 2 & 1 & Partially separated cyst wall (Remnant of cyst) \\
$\mathbf{6}$ & 1 & 1 & 2 & 1 & Separated cyst wall \\
$\mathbf{7}$ & 1 & 1 & 2 & 1 & Absent \\
$\mathbf{8}$ & 1 & 1 & 2 & 1 & Absent \\
\hline \hline
\end{tabular}

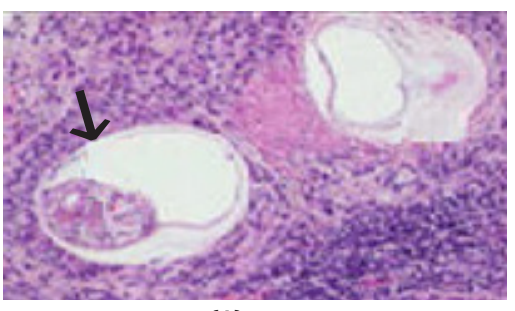

(A)

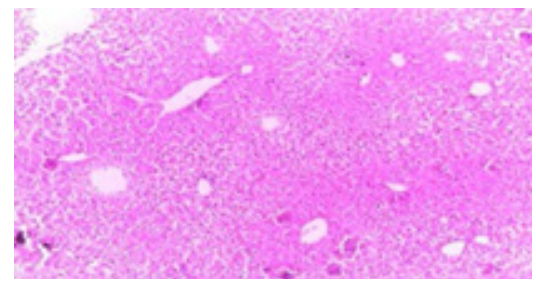

(D)

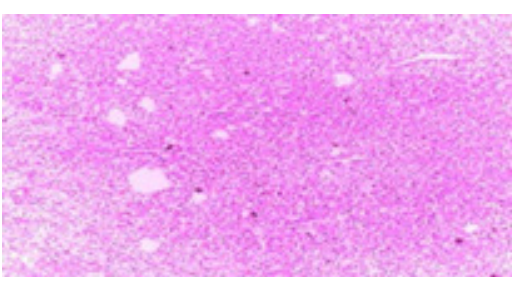

(G)

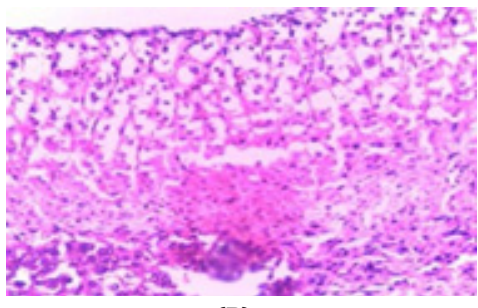

(B)

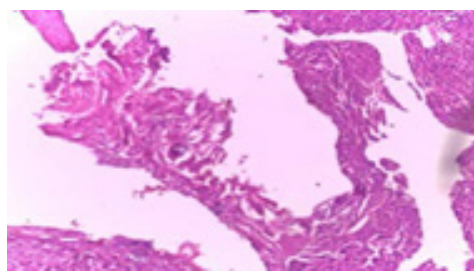

(E)

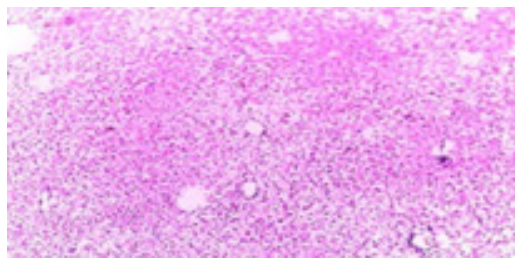

(H)

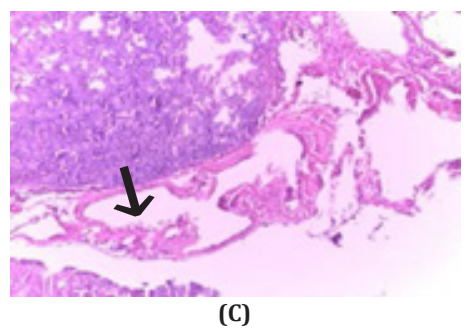

(C)

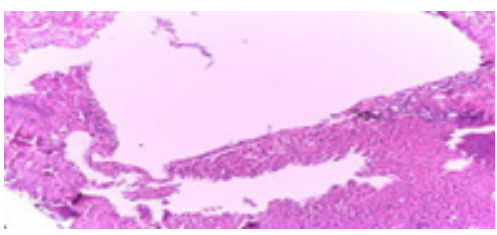

(F)

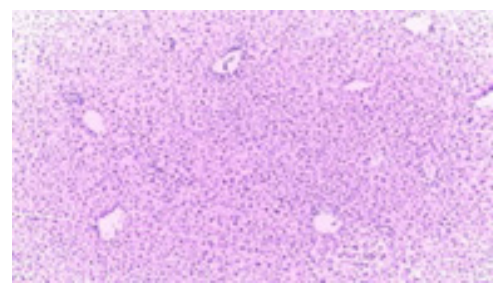

(I)

Fig. 1. Histopathological studies: Hepatic tissue showed (A) Hydatid cyst and germinative layer with scoleses (arrow) surrounded by marked inflammatory reaction of lymphocytic cells in G3 (x100). (B) Mild inflammatory cells, lymphocytes, plasma cells and moderate degeneration in G3 (x400). (C) Partial separation of hydatid cyst wall (arrow) and remnants of cyst in G3 (x100). (D) Moderate inflammatory cells, moderate congestion and moderate degeneration in G4 ( (x100). (E) Remnants of hydatid cyst with moderate inflammatory cells and moderate degeneration in G4 (x100). (F) Separated hydatid cyst wall with mild inflammatory cells and moderate degeneration in G4 (x100). (G) Mild inflammation, congestion, and mild degeneration with absence of hydatid cyst in G5 (x100). (H) Mild inflammatory cells, mild congestion, and moderate degeneration in G6 (x100). (I) Mild inflammatory cells, mild congestion, and mild degeneration in G7 (x100).

\section{DISCUSSION}

Previous studies proved the strong scolicidal effect of NSO extracts on the protoscoleces of hydatid cysts in vitro ${ }^{[26,27]}$. It is known that CS NPs are natural materials with many physicochemical, antimicrobial, and biological properties, that are not toxic for humans. The prospect of using CS NPs as carriers paved way for development of wide variety of delivery vehicles ${ }^{[28]}$. Additionally, CS NPs can cross biological barriers to protect macromolecules from degradation in biological media. It can also deliver drugs or macromolecules by controlled release to a target site ${ }^{[29,30]}$. In our study, we loaded the drugs on these particles to evaluate their treatment efficacy.

Our histopathological study revealed inflammatory changes in liver with infiltration of inflammatory cells, necrotic changes, hydropic degeneration, congestion, and dilatation or widening of the sinusoids mainly in the infected non treated group and to some extent in the treated groups. These results are similar to the histopathological picture of the liver of experimentally infected mice ${ }^{[23]}$ and naturally infected sheep ${ }^{[31]}$. The hydatid cyst stimulates a host inflammatory reaction that ends in the formation of a fibrous capsule ${ }^{[32]}$; and 
the areas in between cysts usually show congestion, liver cell necrosis together with fibrosis and inflammatory infiltration $^{[32]}$, dilatation of the sinusoids and the central veins $^{[33]}$. In the present work, the outcomes revealed improvements in congestion, necrosis, degeneration, and the inflammatory infiltrates in all the treated groups. However, treatment with NSO, ABZ + NSO, ABZ loaded on CS NPs and NSO loaded on CS NPs were slightly better than ABZ alone. The best treatment results were obtained with the combination of ABZ loaded on CS NPs and NSO loaded on CS NPs. Moreover, liver cell necrosis and inflammation were improved with NSO treatment indicating the potential safety of NSO in vivo which agrees with Hassan et al., and Ahmed ${ }^{[34,35]}$, who reported the role of NSO in inhibition of hepatotoxicity.

In conclusion, NSO has marked curative effect on CE in experimentally infected mice. Loading of NSO and ABZ on CS NPs greatly improved their anti-hydatid properties by increasing the drug delivery to the tissues. NSO treatment in combination with ABZ improved the ABZ effect and seemed to be more efficient and could constitute a good candidate in the treatment of CE. These results are corroborated by Kishik et al. ${ }^{[36]}$ who stated that NSO has a promising effect on CE when used alone or in combination with ABZ and its effect was improved when loaded on CS NPs. Our study asserts the role of CS NPs in increasing the efficacy of the drugs either due to their role in the treatment or as drug carrier.

Further in vitro studies are recommended to evaluate CS NPs efficacy utilizing electron microscopy for detailed description of scolices morphological changes using different CS NPs concentrations.

Authors' contribution: Ali HSM and Kishik SM collected the scientific data, conceived the study, and wrote the manuscript; Nagati IM, Ali IR, Aly NSM, Fawzy MM shared in the study design; IR Ali prepared the nanoparticles. All authors revised the manuscript.

Conflict of interest: The authors declare that they have no conflict of interest.

Financial support and sponsorship: This research did not receive any specific grant from funding agencies in the public, commercial, or not-for-profit sectors.

\section{REFERENCES}

1. Torgerson PR. The economic effects of echinococcosis. Acta Trop 2003; 85(2):113-118.

2. Gholami SH, Rahimi-Esboei B, Ebrahimzadeh MA, Pourhajibagher M. In vitro effect of Sambucus ebulus on scolices of hydatid cysts. Eur Rev Med Pharmacol Sci 2013; 17(13):1760-1765.

3. Sanjay OP, Tauro DI, Kilpadi K. Intra-operative anaphylaxis caused by a pulmonary hydatid cyst. J Thor Cardiov Surg 2003; 19(2): 128-129.

4. Haghani A, Roozitalab A, Safi SN. Low scolicidal effect of Ocimum bacilicum and Allium cepa on protoccoleces of hydatid cyst: an in vitro study. Comp Clin Pathol 2014; 23:847-853.

5. Stojkovic M, Zwahlen M, Teggi A, Vutova K, Cretu CM, Virdone R, et al. Treatment response of cystic echinococcosis to benzimidazoles: a systematic review. PLoS Negl Trop Dis 2009; 3: e524.

6. Alvela-Suárez L, Velasco-Tirado V, Belhassen-Garcia M, Novo-Veleiro I, Pardo-Lledías J, Romero-Alegría A et al. Safety of the combined use of praziquantel and albendazole in the treatment of human hydatid disease. Am J Trop Med Hyg 2014; 90:819-822.

7. Ziaee T, Moharreri N, Hosseinzadeh H. Review of pharmacological and toxicological effects of Nigella sativa and its active constituents. J Med Plants 2012; 2(42):16-42.

8. Ali BH, Ziada A, Blunden G. Biological effects of gum arabic: a review of some recent research. Food Chem Toxicol, 2009; 47(1):1-8.

9. Zibaei M, Sarlak A, Delfan B, Ezatpour B, Azargoon A. Scolicidal effects of Olea europaea and Satureja khuzestanica extracts on protoscolices of hydatid cysts. Korean J Parasitol 2012; 50(1): 53-56.

10. Skuhala T, Trkulja V, Runje M, Vukelic D, Desnica B. Albendazole sulphoxide concentrations in plasma and hydatid cyst and prediction of parasitological and clinical outcomes in patients with liver hydatidosis caused by Echinococcus granulosus. Croat Med J 2014; 55(2):146-155.

11. Cong TT, Faivre V, Nguyen TT, Heras H, Pirot F, Walchshofer $\mathrm{N}$, et al. Study on the hydatid cyst membrane: Permeation of model molecules and interactions with drug-loaded nanoparticles. Int J Pharm 2008; 3531(2): 223-232.

12. Said DE, ElSamad LM, Gohar YM. Validity of silver, chitosan and curcumin nanoparticles as anti-Giardia agents. Parasitol Res 2012; 111:545-554.

13. Ali $M$, Afzal $M$, Verma M, Misra-Bhattacharya S, Ahmad FJ, Dinda AK. Improved anti-filarial activity of ivermectin in chitosan-alginate nanoparticles against human lymphatic filarial parasite, Brugia malayi. Parasitol Res 2013; 112(8):2933-2943.

14. Etewa SE, El-Maaty DAA, Hamza RS, Metwaly AS, Sarhan MH, Abdel-Rahman SA et al. Assessment of spiramycin-loaded chitosan nanoparticles treatment on acute and chronic toxoplasmosis in mice. J Parasit Dis; 2018 42(1):102-113.

15. Sharafeldin KM. The physiological impact of ginger, Zingiber officinale and black seed oil, Nigella sativa L. as medicinal plants in gamma-irradiated rats. Egypt J Exp Biol (Zoo.) 2015; 11(2):185-192.

16. Soliman MFM, El-Shenawy NS. Evaluation of the protective effect of two anti-oxidative agents in mice experimentally infected with Schistosoma mansoni hematological and histopathological aspects. Pak J Biol Sci 2003; 6(10):887-897.

17. Atayi Z, Borji H, Moazeni M, Saboor-Darbandi M, Heidarpour M. Zataria multiflora would attenuate the hepatotoxicity of long term albendazole treatment in mice with cystic echinococcosis. Parasitol Int 2018; 6(2):184-187. 
18. Ohya Y, Shiratani M, Kobayashi H, Ouchi T. Release behavior of 5-fluorouracil from chitosan-gel nanospheres immobilizing 5-fluorouracil coated with polysaccharides and their cell specific cytotoxicity. J Macromol Sci Part A 1994; 31(5):629-642.

19. Labsi M, Khelifi L, Mezioug D, Soufli I, Touil-Boukoffa C. Anti-hydatic and immunomodulatory effects of Punica granatum peel aqueous extract in a murine model of echinococcosis. Asian Pac J Trop Med 2016; 9(3):211-220.

20. Amri M, Touil-Boukoffa C. A protective effect of the laminated layer on Echinococcus granulosus survival dependent on upregulation of host arginase. Acta Trop 2015; 149:186-194.

21. Sadjjadi SM, Zoharizadeh MR, Panjeshahin MR. In vitro screening of different Allium sativum extracts on hydatid cysts protoscoleces. J Invest Surg 2008; 21(6):318-322.

22. Al-Qaoud KM, Abdel-Hafez SK. The induction of $\mathrm{T}$ helper type 1 response by cytokine gene transfection protects mice against secondary hydatidosis. Parasitol Res 2008; 102(6):1151-1155.

23. Urrea-París MA, Moreno MJ, Casado N, RodríguezCaabeiro F. Relationship between the efficacy of praziquantel treatment and the cystic differentiation in vivo of Echinococcus granulosus metacestode. Parasitol Res 2002; 88(1):26-31.

24. Al-Kuraishi AH, Histopathological changes of experimental hydatidosis in liver and spleen of albino mice: age and sex effect. J Fac Med Baghdad 2009; 51(4):423-428,

25. Mekonnen GA, Ijzer J, Nederbragt H. Tenascin-C in chronic canine hepatitis immunohistochemical localization and correlation with necro-inflammatory activity, fibrotic stage, and expression of alpha-smooth muscle actin, cytokeratin 7 , and $\mathrm{CD}^{+}$cells. Vet Pathol 2007; 44(6): 803-813.

26. Mahmoudvand H, Asadi A, Harandi MF, Sharififar F, Jahanbakhsh S, Dezaki ES.: In vitro lethal effects of various extracts of Nigella sativa seed on hydatid cyst protoscoleces. Iran J Basic Med Sci 2014; 17(12):10011006.
27. Mahmoudvand H, Dezaki ES, Kheirandish F, Ezatpour B, Jahanbakhsh S, Harandi MF. Scolicidal effects of black cumin seed (Nigella sativa) essential oil on hydatid cysts 2014; Korean J Parasitol 52 (6):653-659.

28. Malmiri HJ, Jahanian MAG, Berenjian A. Potential applications of chitosan nanoparticles as novel support in enzyme immobilization. Am J Biochem Biotechnol 2012; 8(4):203-219.

29. Lopez-Leon T, Carvalho ELS, Seijo B, Ortega-Vinuesa JL, Bastos-Gonzailez D. Physicochemical characterization of chitosan nanoparticles: electrokinetic and stability behavior. J Colloid Interface Sci 2005; 283(2):344351.

30. Perera U, Rajapakse N. Chitosan nanoparticles: preparation, characterization, and applications. In: Kim SK (Editor) Seafood processing by-products: trends and applications. Springer, New York, 2013; 371-387.

31. Beigh AB, Darzi MM, BashirS, Shah A, Shah SA. Gross and histopathological alterations associated with cystic echinococcosis in small ruminants. J Parasit Dis 2017; 41(4):1028-1033.

32. Solcan C, Solcan G, Ionita M, Hristescu D V, Mitrea IL. Histological aspects of cystic echinococcosis in goats. Sci Parasitol 2010; 11(4):191-198.

33. Singh BB, Sharma JK, Tuli A, Sharma R, Bal MS, Aulakh RS, et al. Prevalence and morphological characterization of Echinococcus granulosus from north India. J Parasitol Dis, 2014; 38(1):36-40.

34. Hassan AS, Ahmed JH, Al-Haroon SS. A study of the effect of Nigella sativa (Black seeds) in isoniazid (INH)-induced hepatotoxicity in rabbits. Indian J Pharmacol 2012; 44(6):678-682.

35. Ahmed ZA. Protective Effect of Nigella sativa oil against $\mathrm{CCl} 4$-induced hepatotoxicity in rats. Am J Chin Med, 2010; 8(2):46-55.

36. Kishik SM, Nagati IM, El Hayawan IA, Ali IR, Aly NSM, Fawzy MM, et al. Efficacy of Nigella sativa oil and its chitosan loaded nanoparticles on experimental cystic echinoncoccosis with immunological assessment. PUJ 2020; 13(3) 172-178. 